\title{
Food habits of the population of Kenitra city
}

\author{
Rahma Erahioui ${ }^{1, *}$, Hassna Jaber ${ }^{1}$, Sultana Inekach ${ }^{1}$, Noureddine Rhaim ${ }^{1}$, Zakaria Mennane ${ }^{2}$ and \\ Mohammed Ouhssine ${ }^{1}$ \\ ${ }^{1}$ Laboratory of Agrophysiology, Biotechnology, Environment and Quality University Ibn Tofail, Po Box 133, \\ Kenitra, Morocco \\ ${ }^{2}$ Laboratory of Biology and health University Abdelmalek Assaadi, Po Box 2117, Tetouan, Morocco
}

\begin{abstract}
The Moroccan diet is the Mediterranean characterized by a nutritional model that has remained constant in time and space (main ingredients are olive oil, cereals, fresh or dried fruits, and vegetables...). This study's main objective is to reveal the eating habits, the food combination, and the different types of meals that the Kenitra city population is most adopted through a questionnaire filled in by the participants. An investigation is being carried out from June to August 2018 in Kenitra city. This gives information about the composition of meals taken in Moroccan households. The study covered a sample of 510 homes. Analysis of the results showed that the consumption of raw vegetables in salads and an acidic character was the most frequent. It represents $41.2 \%$ of the rest of the salads consumed by the target population. The inclusion in the salad of ingredients with an acid-base character takes second place with a percentage of $19.6 \%$. Salads with essential characteristics took third place, with $17.1 \%$.

Regarding the consumption of salads in which specific ingredients are cooked. It emerges from the results that salads with an acid character are the most consumed. The percentage obtained in this case is $54.1 \%$. The salads with acid-base characteristics are consumed by the respondents, with a ratio of $26.5 \%$ to occupy the second position. Salads of this category having a primary character are eaten with a frequency of $19.4 \%$. The combinations are characterized by their acidity, which can cause serious digestive problems for the consumer.
\end{abstract}

Keywords: Survey; Households; Vegetables; Eating habits.

\section{Introduction}

In recent decades, eating habits have changed ${ }^{1}$; the food consumption model in Morocco is mostly dominated by cereals, particularly bread, couscous, and pasta. Vegetables and fruits come second ${ }^{2}$. Nutrition education regarding fresh produce intake benefits can improve diet quality and increase Farmers' Market Nutrition Program participation ${ }^{3}$. In Morocco, the number of meals per day is mainly three. In France, several surveys are carried out on representative national samples. We cite the Association Sucre Products communication and consumption survey of 1993-1994 ${ }^{4}$. French meals are varied. But certain foods, taken in incompatible combinations can be harmful to the health of the citizen ${ }^{5}$. Moreover, healthy eating habits represent a significant protective factor against developing noncommunicable diseases, such as diabetes, cardiovascular disease, and cancer ${ }^{6}$.

Food combinations must be based on the principle of digestive physiology ${ }^{7}$. Scientific studies have shown that certain food combinations influence the bioavailability of nutrients in the intestine and delay

*Corresponding author: Rahma Erahioui

Email address: rahma.erahioui@uit.ac.ma

DOI: http://dx.doi.org/10.13171/mjc10802011041527re human digestion operation ${ }^{8}$. Thus, it is crucial to choose the right food combination to provide vitality, human beings' performance, and longevity ${ }^{9}$.

The Moroccan population's diet has known several changes at the level of the compositions and the periods of the meals and the direction towards the ostentation, which poses digestive problems ${ }^{10}$. Thus our stomach is our second brain the treatment of this subject has become essential to face these problems of public health resulting from our food habits ${ }^{11}$.

The most promising targets for functional food science are gastrointestinal amelioration functions, redox, antioxidant systems, and macronutrients' metabolism ${ }^{12}$. Ongoing research into functional foods will allow the establishment of health claims that can be translated into messages for consumers to reduce disease risk ${ }^{13}$. Acceleration of progress in nutrition will require significant, large-scale nutrition-sensitive programs that address key underlying determinants of nutrition and enhance the coverage and effectiveness of nutrition-specific interventions ${ }^{14}$. Therefore, this study's main objective is to reveal the eating habits, the food

Received August 9, 2020

Accepted September 17, 2020

Published November 4, 2020 
combination, and the different types of meals that the population of Kenitra city is most adopted through a questionnaire filled by the participants.

\section{Experimental}

Our survey was carried out from June to August 2018. The number of participants is 510 people, aged from 12 to 71 with a percentage of women $67,2 \%$, and men $32,8 \%$ were prospectively included in the study. For those under 18 years, we are based on the permission of their parents.

The inclusion criteria identify the study population as healthy people who do not suffer from digestive or other diseases and are not on a diet. The exclusion criteria are those who are sick and on a diet. A questionnaire consisting of 18 questions constitutes yes, and no question or QCM question evaluating the quality of the meal of consumers in Kenitra city. The validation of our survey was done by the scientific professors of university Ibn Tofail. The questionnaire was filled orally and covered different criteria. In return, information on the meals constitution, the raw vegetables (cucumber, tomato, onion, beet, potato, rice, egg, tuna, and mayonez...) and fruits (apples, bananas, oranges...), cooked meals (tagine with vegetables and poultry or with vegetables and red meat...). The other types of cooked Food include herbal teas, coffee, tea, and all the results collected, sorted, and processed by the statistical software Microsoft Office Excel 2007.

\section{Results and Discussion}

\subsection{Consumption of raw vegetables}

In Figure 1, the diet of raw vegetable consumption among the inhabitants of the city of Kenitra differs from one family to another. The consumption of vegetables in the natural state is not generalized among all the respondents in Kenitra city. The group that consumes the raw one to three times per week represents $21.8 \%$. The group that consumes 4 to 7 times per week represents $29 \%$. The group which consumes 8 to 11 times per week constitutes only $9.4 \%$, and finally, the group which consumes raw vegetables 12 to 14 times per week is found with the representativeness of $8.8 \%$. However, those who no longer pay attention to the raw material, that is to say, they do not consume the raw material, constitute $31 \%$ of all respondents.

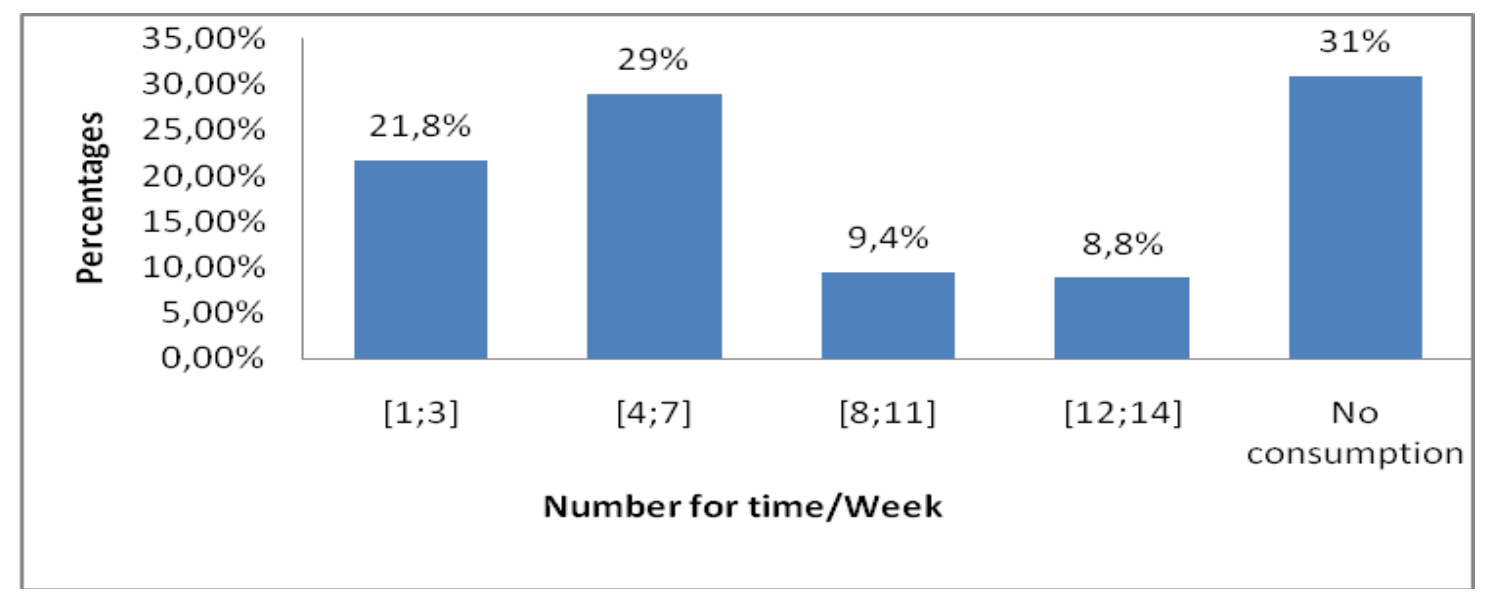

Figure 1. Percentage of raw vegetable consumption per week

\subsection{Consumption of vegetables in combinations}

Consumption of raw vegetables is beneficial for health, especially if prepared with the right combination ${ }^{15}$. Otherwise, any other combination can disrupt the digestive system's functions, lead to bloating acidity problems, and poor assimilation of vitamins ${ }^{16}$. The respondents declared all of these findings.

The diagram below shows that the percentage of salads' consumption with an acid character is dominant $(41.17 \%)$. The second place is occupied by those who consume salads with a total absence of rawness. This group represents $22.15 \%$ of the surveyed population. This group is followed by a third who chose the consumption of acid-base salad $(19.6 \%)$. And finally, in fourth place, people consume salads of a fundamental nature $(17.08 \%)$ (Figure 2). 


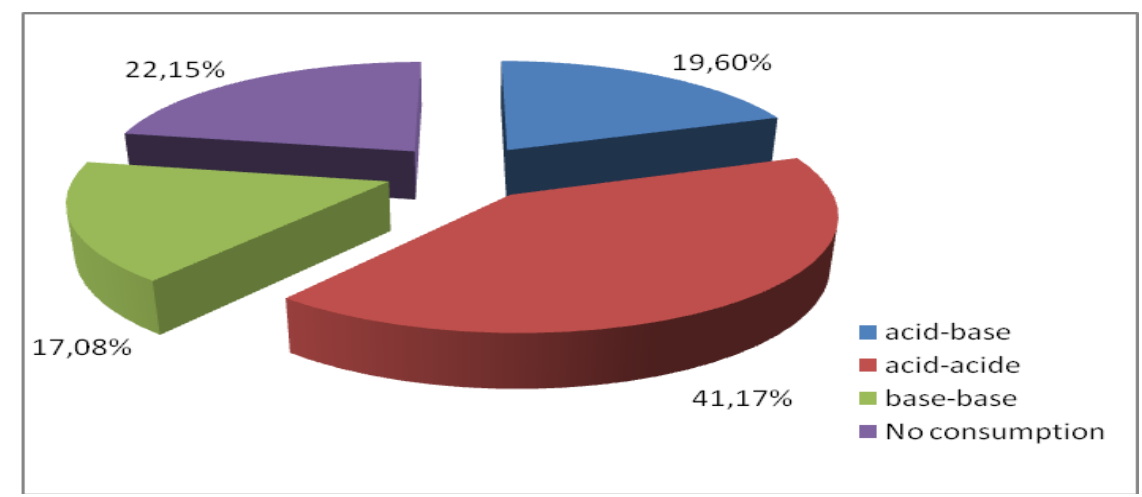

Figure 2. Percentage consumption of various combinations of raw vegetables

\subsection{Vegetable consumption per week}

The consumption of vegetables one to three times/week is declared by $21.8 \%$ of the respondents. The consumption of raw 4 to 7 times/week was
$32.4 \%$ for the second group. Those who consume 8 to 11 times raw per week are $9.4 \%$, and only $9 \%$ of the population consume abundant raw with 12 to 14 times per week (Figure 3).

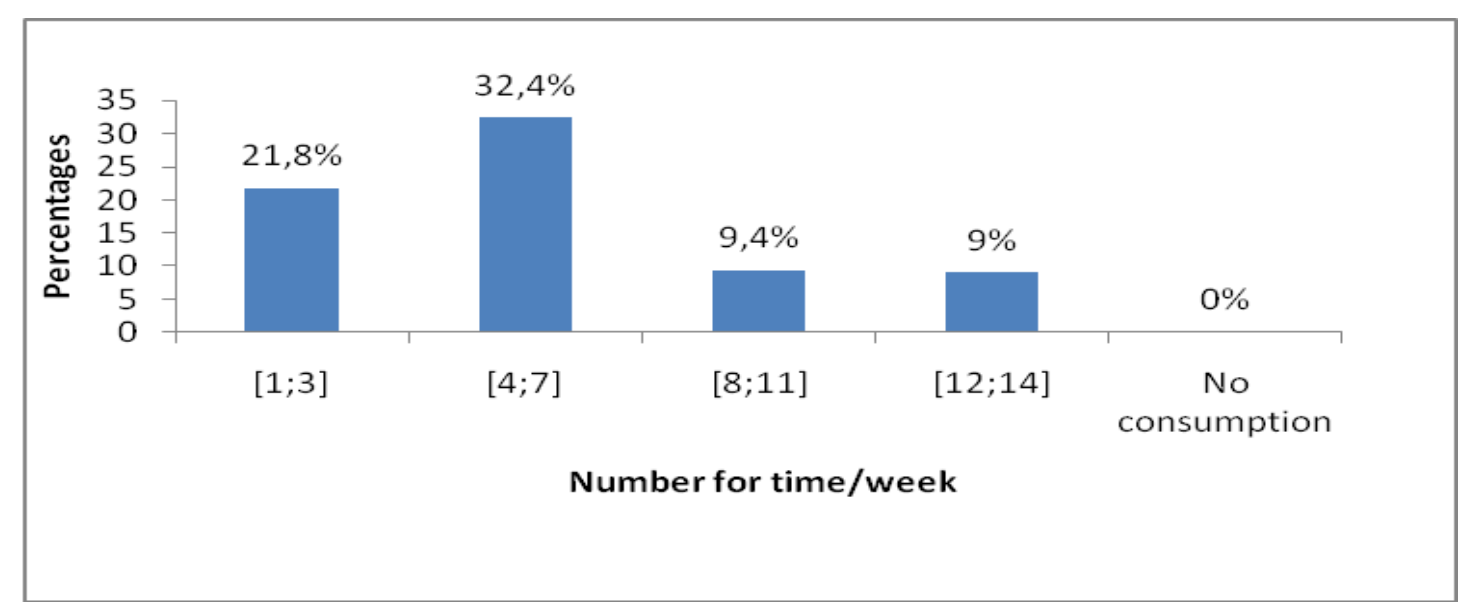

Figure 3. Percentage consumption of raw vegetables in combinations/week

\subsection{Food associations}

The analysis of the different food associations is shown in the following Figure 4. The acid-acid food association is the most common in household meals in Kenitra, with $54.11 \%$. In the second position comes the acid-base association, the percentage of which is $26.47 \%$. The base-base combination is in the last place, with $19.41 \%$.

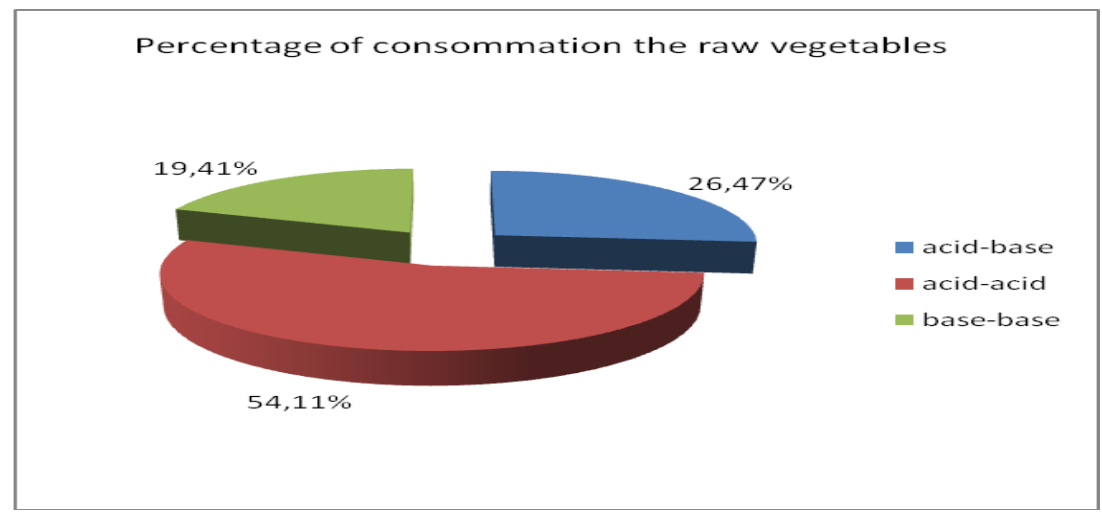

Figure 4. Percentage of combinations of cooked vegetables consumed

\subsection{Consumption of animal protein and cooked vegetables}

At this level, the survey showed that the association in the same dish of meat and cooked vegetables was a ritual for two-thirds of the surveyed population (69.8\%). Those who do makeup 30.2\% (Figure 5). 


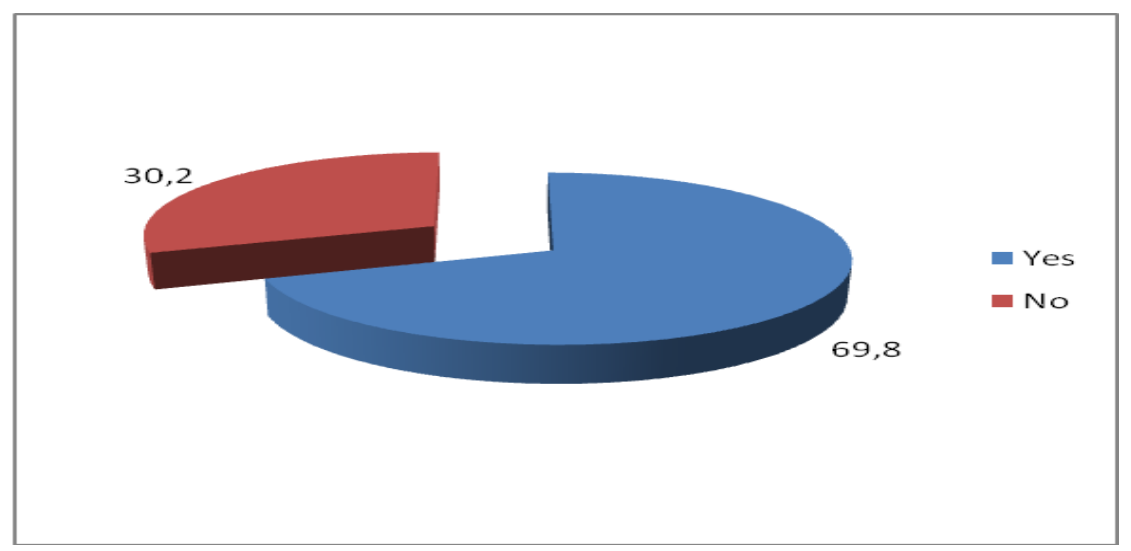

Figure 5. Percentage of cooked meat + cooked vegetable consumption

Figure 6 below shows a variation in the frequency of preparation of this type of meal per week. We have found households that consume 4 to 7 times the meat with vegetables with a percentage of $38.3 \%$. Those who consume it 1 to 3 times a week represent $24.1 \%$ of the surveyed population. Some households prepare their meals of meat with vegetables 8 to 11 times a week. This group represents $10.8 \%$ of all respondents. The proportion of those who consume meat with vegetables 12 to 14 times a week is $9 \%$.

It should be noted that $17.8 \%$ of the population declared that they do not consume meats with vegetables.

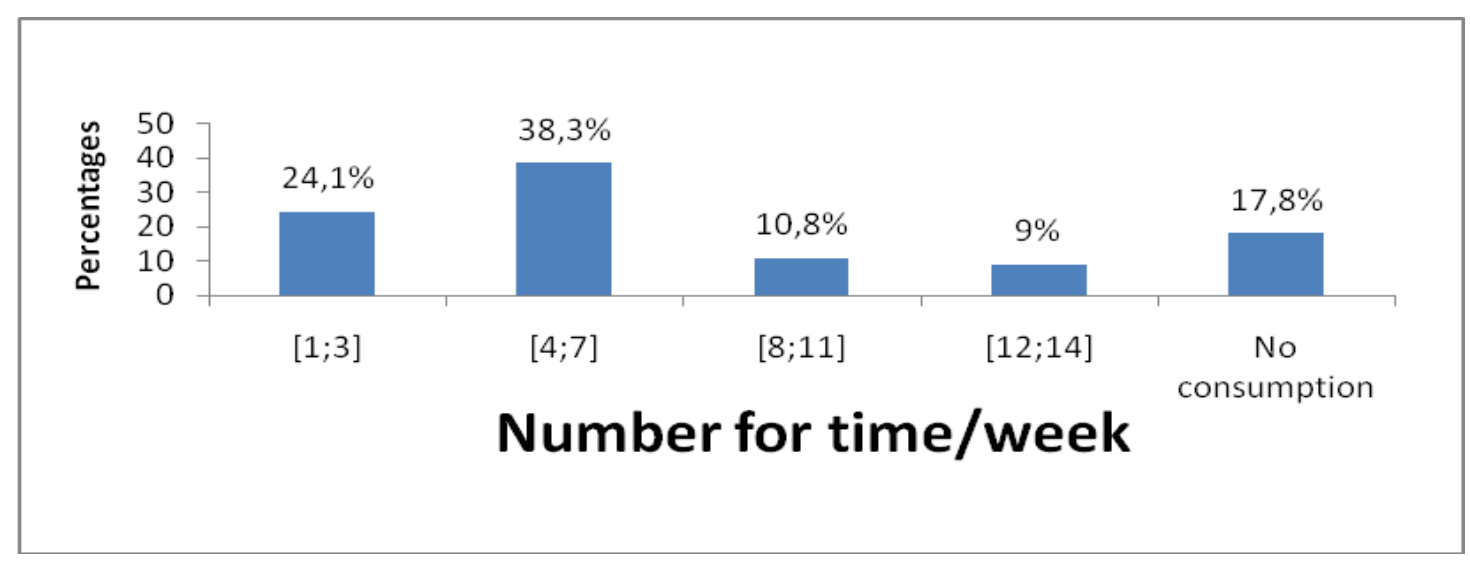

Figure 6. Percentage of cooked meat + cooked vegetables/week consumption

\subsection{Consumption of meat alone}

The consumption of meat alone is recorded in
$47.84 \%$ of the surveyed population. The remaining declares not consume meat only, 52.16\% (Figure 7).

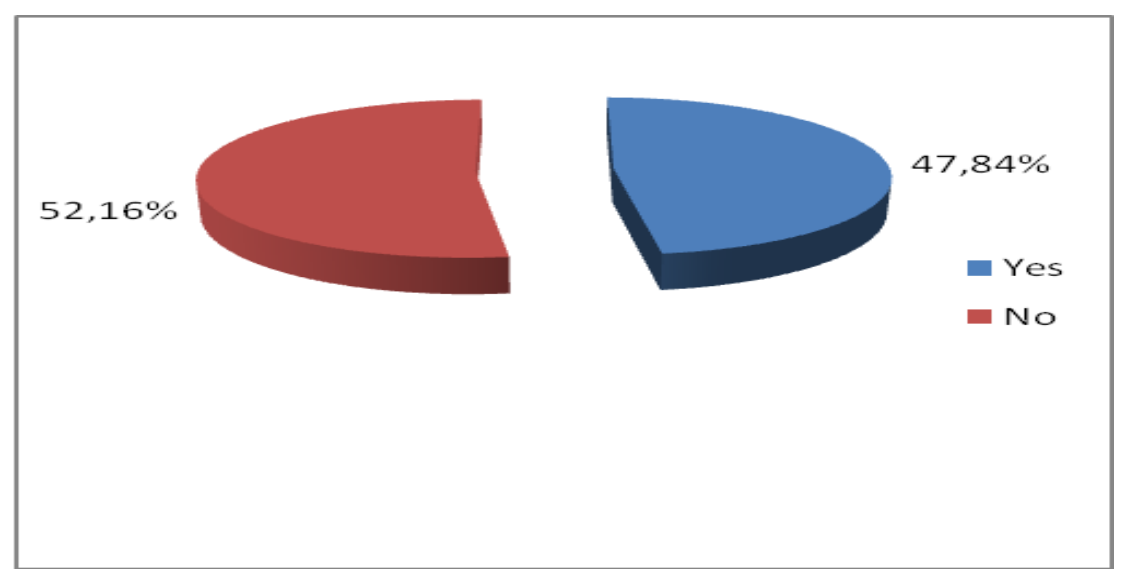

Figure 7. Consumption of meat alone

The following diagram (8) shows the frequency of meat consumption per week. We separated five classes: [100 to $200 \mathrm{~g}$ ], [300 to $400 \mathrm{~g}$ ], [500 to $600 \mathrm{~g}$ ],
[700 to $800 \mathrm{~g}$ ], [900 to $1000 \mathrm{~g}$ ] to treat the subject. The frequency relating to each class is in the order of $21.8 \% ; 18.4 \% ; 12 \% ; 0.4 \% ; 7.8 \%$. The rest said they 
didn't know how much meat they eat per week. This group represents $32 \%$ of the surveyed population. We also found that $7.6 \%$ of respondents do not consume meat. For example, the bad food combination of meat is eggs and fried meat. In recent years some epidemiological studies have associated the overconsumption of red meat with the development of cardiovascular disease and colon cancer ${ }^{17}$.

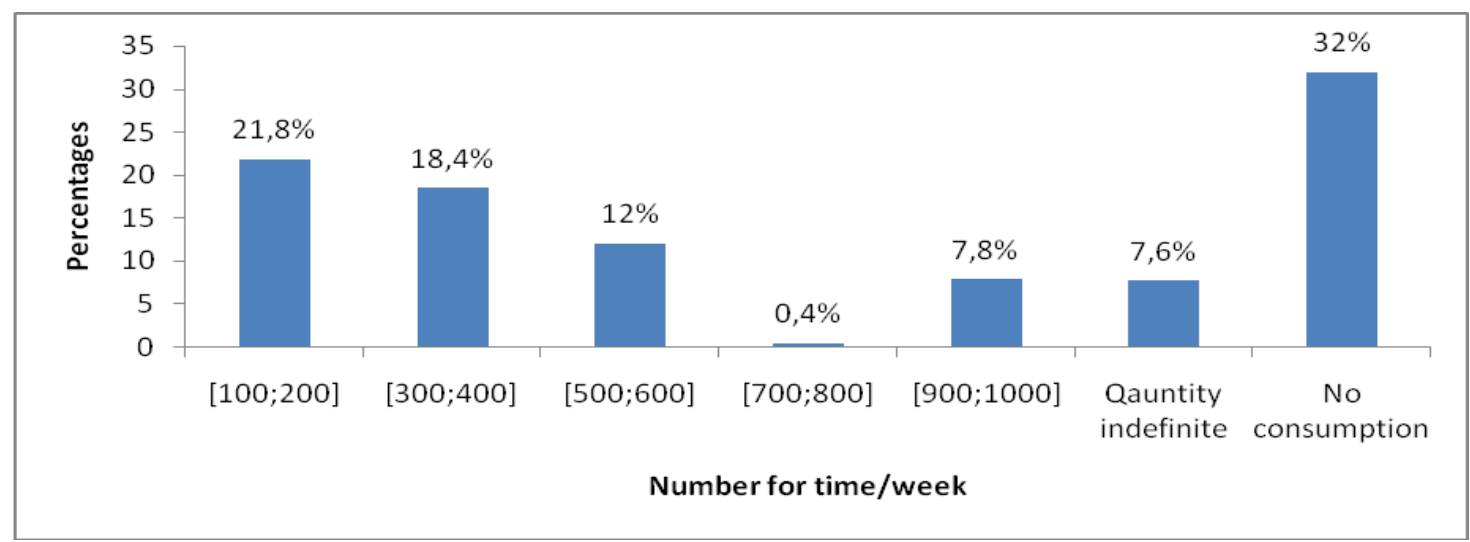

Figure 8. Meat consumption / day

\subsection{Fruit consumption after the meal}

The fruit consumption per week is [1 to 3], [4 to 7], [8 to 11], [12 to 14]. The results are presented in Figure 9. The percentage relating to each class is respectively $23.9 \% ; 38.8 \% ; 9.7 \% ; 11.3 \%$ and $16.3 \%$.
It should be noted that the class of households that consume fruit 4 to 7 times per week is the most widespread. It represents $38.82 \%$ of the entire population surveyed (Figure 9).

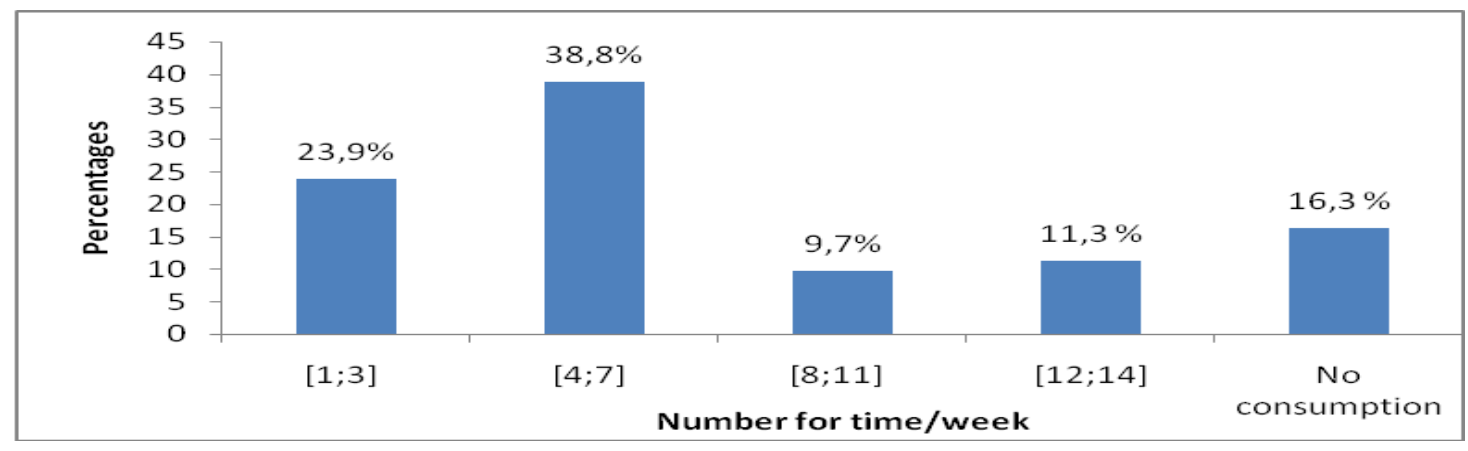

Figure 9. Percentage of fruit consumption/week

\subsection{Consumption of fish combined with other} meals

For the combination of fish with other meals, only
$37.7 \%$ who answered yes. While $62.3 \%$ of respondents consume fish alone (Figure 10).

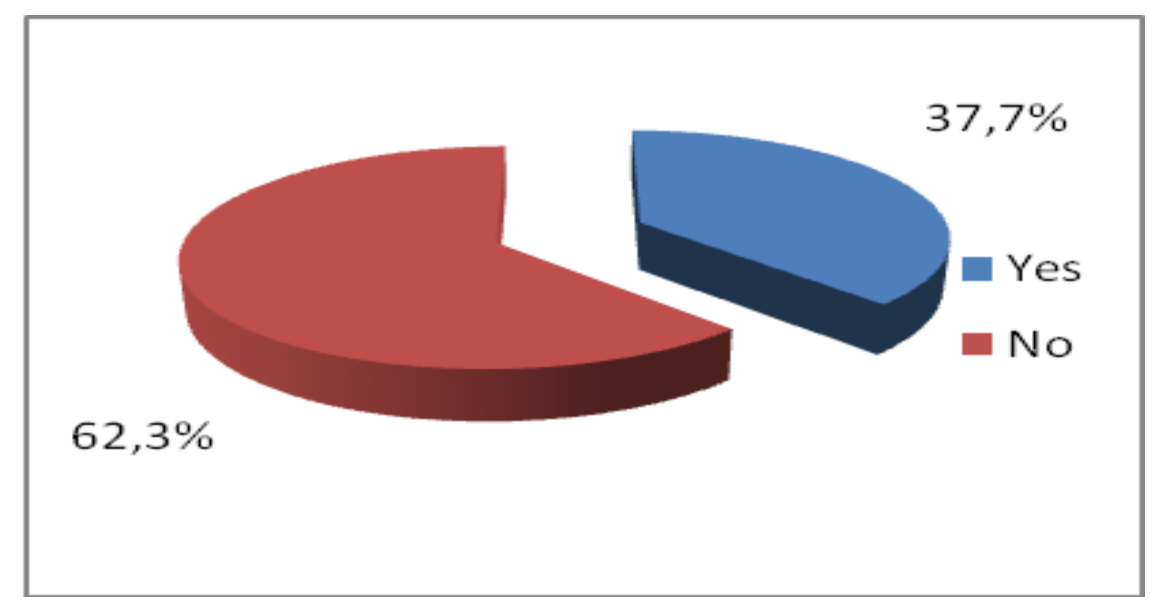

Figure 10. Percentage of fish consumption + meal 


\subsection{Milk coffee consumption}

The rate of people who consume coffee with milk is slightly higher $(54.1 \%)$ compared to those who said no to taking coffee with milk (45.9\%) (Figure 11).

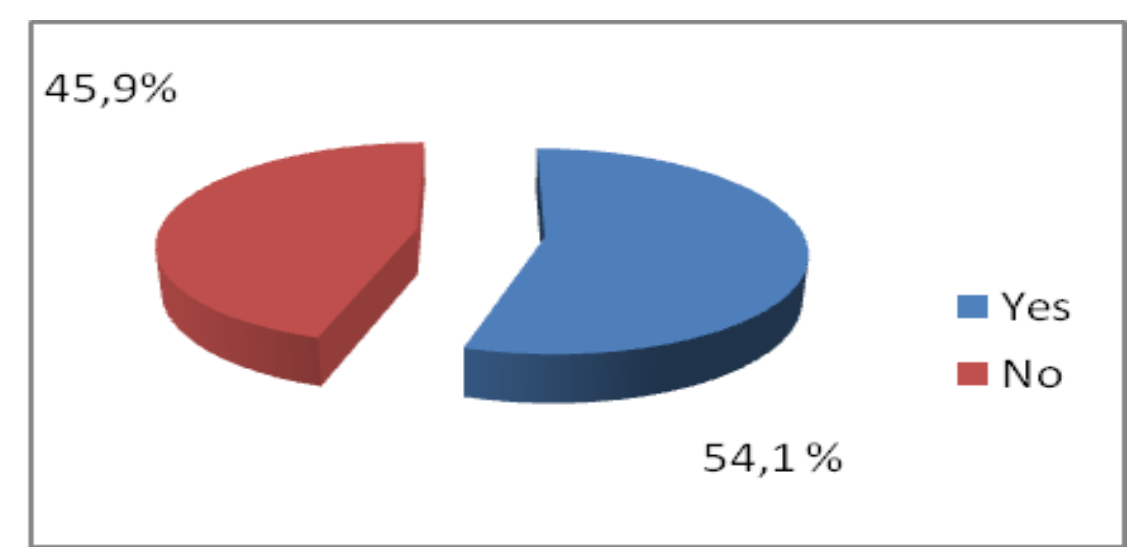

Figure 11. Percentage of coffee + milk consumption

3.10. Consumption of tea during meals

Moroccans usually take tea with meals, and consequently, $60 \%$ of respondents consume it, while the rest do not (Figure 12).

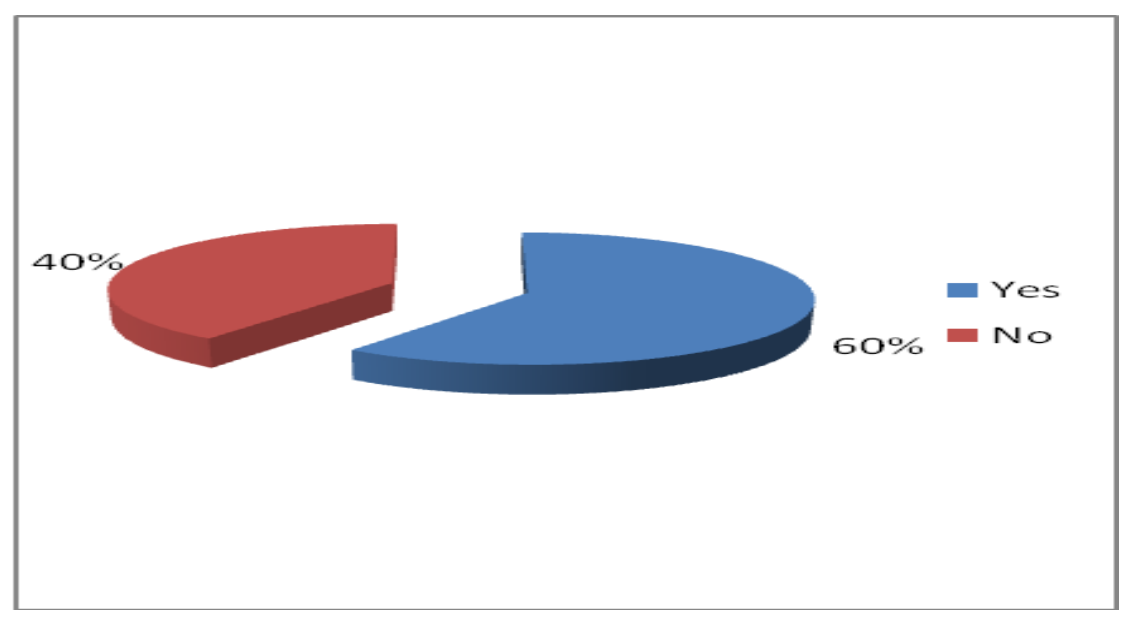

Figure 12. Percentage of tea consumption during meals

\subsection{Consumption of soft drinks}

The high consumption of non-alcoholic beverages (i.e., sugary or sweetened drinks) leads to eating behavior problems and diseases leading to obesity ${ }^{18}$.
The percentage of the population consuming soft drinks is slightly higher than those who do not. The first group is represented by $54.9 \%$, and the second group is still lower compared to the first with $45.1 \%$ (Figure13).

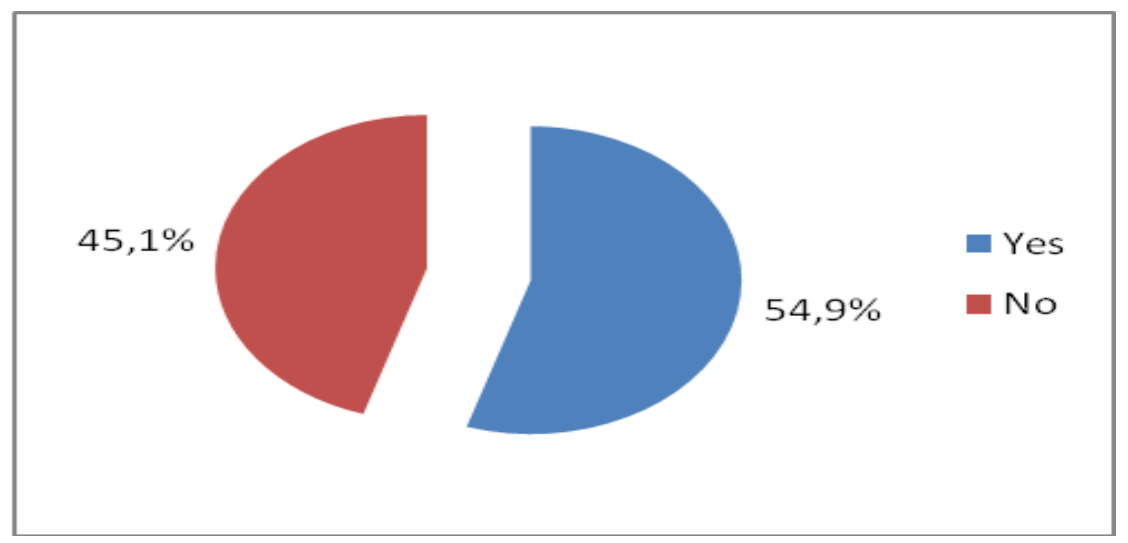

Figure 13. Percentage of soft drink consumption 
Recent scientific studies show that soft drinks are dangerous for our health ${ }^{19}$. The awareness-raising actions must be amplified for more involvement in reducing the consumption of problem drinks.

The consumption knows Moroccan households of three main meals with a predominance of cooked over raw marks. The natural is essentially composed of vegetables (cucumber, tomato, onion, beet, potato, rice, egg, tuna, and mayonez) and fruits (apples, bananas, oranges...) ${ }^{20}$. As for cooked meals, we have found that Kenitrians eat tagine with vegetables and poultry or with vegetables and red meat a lot. Couscous with seven vegetables is a Friday ritual. Some households take it on Sunday. The other types of cooked Food include herbal teas, coffee, tea.

Food combining is an approach to eating that works on the premise that our bodies can only digest one concentrated Food at a time. Focused foods are defined as starches and proteins. So, to simplify it, anything foods other than fruits and vegetables. The digestion of starches (grains, potatoes, and many other roots) requires alkaline conditions, whereas the enzymes that digest proteins thrive in an acidic environment ${ }^{21}$. So, if we eat starch and a protein together, we are asking our digestive systems to be alkaline and acidic at the same time, which is not possible ${ }^{22}$. Unfortunately, many of the typical Western food combinations ask the body to do just that ${ }^{23}$. The Food you eat can affect your health and your risk for certain diseases ${ }^{24}$. Acidic foods will slow it down during the digestion mechanism, giving more trouble to the digesting apparatus, namely stomach acidity, gas, swelling, and heartburn, so we insisted on avoiding acidic food combinations. To eat healthier Food, you may need to change some of your daily habits. You also may need to change some things in your environment. Your environment includes everything around you, like your home or the place you work ${ }^{25}$. Good nutrition can lead to protect our environment ${ }^{26}$ better. According to the various surveys and studies carried out by the Ministry of Health over the past decades, nutritional disorders still constitute a public health problem despite the progress observed in the fight against malnutrition ${ }^{27}$.

\section{Conclusion}

The survey about consumer meals in Kenitra city was carried out on 510 households. This allowed us to shed light on the eating habits of the population of this city.

The consumption knows Moroccan households of three main meals with a predominance of cooked over raw marks. The raw is essentially composed of vegetables (cucumber, tomato, onion, beet, potato, rice, egg, tuna, and mayonez) and fruits (apples, bananas, oranges...). As for cooked meals, we have found that Kenitrians eat tagine with vegetables and poultry or with vegetables and red meat a lot.
Couscous with seven vegetables is a Friday ritual. Some households take it on Sunday. The other types of cooked Food include herbal teas, coffee, tea...

A ready analysis of the raw dish shows the presence of acidic ingredients. We noted in the salad a permanent use of cucumber, tomatoes, onions, and vinegar. The meal, although sour, may be compatible with the physiological nature of the digestive tract.

\section{Acknowledgements}

I thank all my family who support me, my mother, father, sisters, brothers, and friends. Special thanks to Doctor Mohammed Ouhssine for his considerable effort with me to achieve this humble research.

\section{References}

1- K.G. Pot, C.J. Prynne, S. Almoosawi, D. Kuh, A.M. Stephen, Trends in food consumption over 30 years: evidence from a British birth cohort, European journal of clinical nutrition, 2015, 7 , 817-823.

2- F. Allali, Nutrition Transition in Morocco, Integrative Journal of Medical science, 2017, 4, 70-73.

3- M.L. Kropf, D.H. Holben, J.P. Holcomb Jr, H. Anderson, Food security status and produce intake and behaviors of Special Supplemental Nutrition Program for Women, Infants, and Children and Farmers' Market Nutrition Program participants, Journal of the American Dietetic Association, 2007, 107, 1903-1908.

4- S.L. Tamers, T. Agurs-Collins, K.W. Dodd, L. Nebeling, US and France adult fruit and vegetable consumption patterns: an international comparison, European Journal of Clinical Nutrition, 2009, 63, 11-17.

5- A. Robertson, Food and health in Europe: a new basis for action, WHO Regional Office Europe, 2004, 96.

6- M. Egnell, P. Crosetto, T. D'almeida, E. KesseGuyot, M. Touvier, B. Ruffieux, S. Hercberg, L. Muller, C. Julia, Modelling the impact of different front-of-package nutrition labels on mortality from non-communicable chronic disease, International Journal of Behavioral Nutrition and Physical Activity, 2019,16, 56.

7- C. Li, W. Yu, P. Wu, X.D. Chen, Current in vitro digestion systems for understanding food digestion in human upper gastrointestinal tract, Trends in Food Science \& Technology, 2020, 96, 114-126.

8- D. Ercolini, V. Fogliano, Food Design to Feed the Human Gut Microbiota, Journal of Agricultural and Food Chemistry, 2018, 66, 3754-3758.

9- A. Burian, J.M. Nielsen, M. Winder, Food quantity-quality interactions and their impact on consumer behavior and trophic transfer, Ecological Monographs, 2020, 90, e01395. 
10-K. El Kinany, M.M.S. Deoula, Z. Hatime, H.A. Boudouaya, M. Atassi, A. El Asri, A. Benslimane, C. Nejjari, S.A. Ibrahimi, P. Lagiou, K. El Rhazi, Modified Mediterranean diet score adapted to a southern Mediterranean population and its relation to overweight and obesity risk, Public Health Nutrition, 2020, 1-7.

11-Statistics, F. A. O. Food and Agriculture Organization of the United Nations, Retrieved, 2010, 3, 2012.

12-O.T. Olaniyan, G.E. Okotie, In Innovations in Food Technology, Nutritional Physiology, 2020, 395-424.

13-M.B. Roberfroid, Concepts and strategy of functional food science: The European

17-S. Wen, G. Zhou, S. Song, X. Xu, J. Voglmeir, L. Liu, F. Zhao, M. Li, L. Li, X. Yu, Y. Bai, Discrimination of in vitro and in vivo digestion products of meat proteins from pork, beef, chicken, and fish, Proteomics, 2015, 21, 36883698.

18-V.S. Malik, M.B. Schulze, F.B. Hu, Intake of sugar-sweetened beverages and weight gain: a systematic review, The American journal of clinical nutrition, 2006, 84, 274-288.

19-M.A. Cabrera Escobar, J.L. Veerman, S.M. Tollman, M.Y. Bertram, K.J. Hofman, Evidence that a tax on sugar-sweetened beverages reduces the obesity rate: a meta-analysis, BMC Journal Health, 2013, 13, 1072.

20-K. Azekour, Z. Outaleb, M. Eddouks, F. Khallouki, B. El Bouhali, Adherence to the Mediterranean diet of school-age children in Moroccan oases, Draa-Tafilalet Region, East Mediterr Health J, 2020, 26, 1-14.

21-K. Xiong, L. Zhou, J. Wang, A. Ma, D. Fang, L. Xiong, Q. Sun, Construction of food-grade $\mathrm{pH}$ sensitive nanoparticles for delivering functional perspective, The American journal of clinical nutrition, 2000, 6, 1660S-1664S.

14-M.T. Ruel, H. Alderman, Maternal and Child Nutrition Study Group, Nutrition-sensitive interventions and programs: how can they help to accelerate progress in improving maternal and child nutrition? The lancet, 2013, 382, 536-551.

15-J.L. Slavin, B. Lloyd, Health benefits of fruits and vegetables, Advances in nutrition, 2012, 4, 506-516.

16-Y.J. Zhang, S. Li, R.Y. Gan, T. Zhou, D.P. Xu, H.B. Li, Impacts of gut bacteria on human health and diseases, International journal of molecular sciences, 2015, 16, 7493-7519.

food ingredients, Trends in Food Science \& Technology, 2020, 96, 102-113.

22-N. Pellegrini, E. Vittadini, V. Fogliano, Designing food structure to slow down digestion in starch-rich products, Current Opinion in Food Science, 2020, 32, 50-57.

23-J.L. Slavin, L. Beate, Health benefits of Fruits and Vegetables, Advances Nutrition, 2012, 3 , 506-516.

24-C.L. Holden, P. Rollins, M. Gonzalez, Does how you treat yourself affect your health? The relationship between health-promoting behaviors and self-compassion among a community sample, Journal of health psychology, 2020.

25-A.G. Sammarco, B. Orasanu, S.T. Mahajan, The Bladder in MS: A Review, Journal of Neurology \& Neurophysiology, 2014, 5, 1-7.

26-J.F. Sallis, K. Glanz, The role of built environments in physical activity, eating, and obesity in childhood, The future of children, 2006, 16, 89-108.

27-Federal Democratic Republic of Ethiopia, National Nutrition Program 2016-2020, 2016. 